\title{
Survival of lactic acid bacteria from fermented milks in an in vitro digestion model exploiting sequential incubation in human gastric and duodenum juice
}

\author{
T. Faye, A. Tamburello, G. E. Vegarud, and S. Skeie ${ }^{1}$ \\ Department of Chemistry, Biotechnology and Food Sciences, Norwegian University of Life Sciences, PO Box 5003, NO-1432 Ås, Norway
}

\section{ABSTRACT}

In the present study, the survival of 9 lactic acid bacteria (5 Lactococcus strains, 3 Lactobacillus strains, and 1 strain of Enterococcus hirae), was investigated in vitro under conditions similar to human digestion using human gastric and duodenal juices. The tolerance of the bacteria was also tested with traditional methods using acidic conditions and bile salts. The strains were subjected to a model digestive system comprising sequential incubation in human gastric and duodenal juices, in a 2-step digestion assay at $37^{\circ} \mathrm{C}$, simulating the human upper gastrointestinal tract with human gastric juices at $\mathrm{pH} 2.5$ and human duodenal juices at $\mathrm{pH}$ 7. The bacterial strains were tested either as washed cells from culture media or in fermented milk. The initial in vitro testing in acid and bile salts showed that Lactobacillus strains and the E. hirae strain displayed a significantly higher acid tolerance than the lactococci. The lactobacilli and the Enterococcus numbers increased, whereas the lactococci decreased at least 1 $\log$ during the bile salt treatment. The Lactobacillus strains showed the highest survival rate in the model digestive system when washed bacterial cultures were used with a minor log reduction, whereas the lactococci numbers were reduced by at least $\log 4$. However, when using fermented milks in the model digestion system it was demonstrated that the Enterococcus strain and 2 strains of Lactococcus lactis ssp. cremoris benefited significantly from the presence of the fermented milk as food matrix, with $\log$ numbers $>\log 7$ and 5 , respectively, after digestion of the fermented milk. The analyses reported comprise a comprehensive in vitro testing regimen suitable for evaluation of the survival of candidate probiotic bacteria in human digestion as an initial prescreen to clinical trials.

Key words: lactic acid bacteria, survival, human digestive model system, fermented milk

Received July 8, 2011.

Accepted September 30, 2011.

${ }^{1}$ Corresponding author: siv.skeie@umb.no

\section{INTRODUCTION}

In recent decades, there has been growing interest in functional foods containing bacteria with beneficial effects. Products containing functional bacteria or definite probiotics are popular among the consumers and include capsules, tablets, juices, yogurts, fermented milks, and other dairy products. Among food products with probiotics added, fermented milks and yogurts are especially acceptable. An explanation of this popularity can be that these products initially contain relatively large amounts of bacteria, among them several strains with well-known functional properties, which have been regarded as healthy products for a long time. However, the criteria for being considered as probiotic bacteria are several and strict (de Vrese and Schrezenmeir, 2008; Borchers et al., 2009). These criteria include that the bacteria should be of human origin and at least 1 clinical phase study must have been conducted. This implies that several bacterial strains with a long history in food fermentations and with conferred probiotic properties like good survival through the digestive tract, production of exopolysaccharides, antagonism against pathogenic bacteria, or the capability to adhere to the epithelium in the gut, cannot be considered as declared probiotic bacteria. Nevertheless, food-related bacteria with stated positive effects for the consumer are generally accepted as functional ingredients in food products (Pfeiler and Klaenhammer, 2007; Zhu et al., 2009).

Scandinavian ropy milks are traditional fermented milk products from northern Scandinavia (Furuset, 2005, 2008; Fondén et al., 2006). The main characteristic of these products is the slimy texture of the milks caused by growth of exopolysaccharide-producing Lactococcus lactis ssp. cremoris in the fermenting product. According to the tradition in Norway, this ropy milk was produced by adding leaves of the herb butterwort (Pinguicula vulgaris) into the milk before incubation (Furuset, 2005, 2008). Nowadays, a commercial product called Tjukkmjølk is produced based on old starter cultures that are supposed to originate from this herb. Similar products are available in Sweden (Långfil), Finland (Viili), and Iceland (Skyr; Fondén et al., 2006).

Traditionally, the Norwegian ropy milk has a public image of having especially good health-related proper- 
ties. Examples are health sites and debate forums on the internet reporting that people are consuming ropy milks without any adverse effects despite suffering of milk allergy or intolerance. However, although ropy milk may have great potential as a functional dairy product worldwide, only a few scientific studies have investigated ropy milk products or examined the functional potential of the exopolysaccharide-producing lactococci (Nilsson and Nilsson, 1958; Kitazawa et al., 1991, 1993; Nakajima et al., 1992).

One of the main criteria for the assessment of probiotic bacteria is that they survive the hostile environments in the digestive tract to perform their actions in the gut. During the gastrointestinal passage, the probiotic bacteria must tolerate the presence of pepsin and the low $\mathrm{pH}$ of the stomach. Although the $\mathrm{pH}$ in the stomach will increase to a higher level ( $\mathrm{pH} 4-6$ ) depending on the buffering capacity after food intake, it generally stabilizes after some time to 2.5 to 3.5 (Holzapfel et al., 1998). Thereafter, the bacteria must survive the effects of bile salts and the protease-rich conditions of the duodenum (Ekmekcioglu, 2002).

Normally, potentially probiotic bacteria are exposed to standard in vitro testing to examine if they can survive in the digestive tract (Borchers et al., 2009). These tests include exposure of the bacteria to acidic conditions normally between $\mathrm{pH} 2.0$ and 3.5, mimicking the environment in the stomach, and to bile salts. However, these tests give only an indication of the bacterial tolerability of the digestive conditions. During digestion the bacteria encounter multiple severe stress factors that ultimately might affect their survival and subsequent performance in the gut. To determine the actual capability of a bacterium to survive passage through the digestive tract, it is necessary to apply model systems mimicking the human digestive system, accompanied by human clinical trials. In a model system, it is possible to copy the subsequent exposure to all of the conditions bacteria must tolerate in real digestion. Furthermore, the metabolic state and fitness of ingested bacteria in the digestive tract will most probably be influenced by the method used for delivery. Pure bacterial cultures will presumably be more exposed to the severe conditions during digestion than bacteria embedded in food, although the moment the bacteria are exposed to the human digestive tract environment, a dramatic metabolic adjustment will be necessary for them to survive, regardless of how they are administered. However, bacterial cultures might be in a favorable metabolic condition after growth in appropriate media at optimal conditions regarding temperature and oxygen supply, compared with bacterial cells stressed by factors in the foods such as, for instance, limited carbon supply, low
$\mathrm{pH}$, unfavorable redox potentials, and incubation at non-optimal temperatures.

In this paper, we compare the potential of selected lactic acid bacteria to survive gastrointestinal conditions through classical in vitro experiments (testing their tolerance to acidic environments and to bile salts) with a digestive model system using gastric and duodenal juices of human origin, mimicking an in vivo gastrointestinal digestion. By using this digestive model, the bacteria were sequentially exposed to all of the conditions present in the upper part of the human digestive tract. Therefore, this model seems to represent a realistic evaluator of the functional or probiotic potential of the bacteria tested. The suitability of fermented milk as a protective delivery matrix for the bacterial strains through the digestive model system was also investigated.

\section{MATERIALS AND METHODS}

\section{Bacterial Strains}

A total of 9 strains (5 lactococcal, 3 lactobacilli, and 1 enterococcal strain), were examined and propagated as indicated in Table 1. All strains, except for the commercial probiotic strain Lactobacillus rhamnosus GG, were of food origin (Table 1). The 4 strains of Lc. lactis ssp. cremoris originated from Norwegian ropy milks, and produce the exopolysaccharides responsible for the characteristic texture of these products. The strains Lactococcus lactis ssp. cremoris $\mathrm{Bf}-2$ and $\mathrm{Bf}-3$ originated from ropy milks made from sterile skim milk inoculated with Pinguicula vulgaris. All strains were identified to species level using 16S rDNA gene sequencing (Østlie et al., 2004) and sequences were edited using BioEdit software (http://www.mbio.ncsu.edu/BioEdit/bioedit. html) and analyzed using the BLAST sequence search tool (http://blast.ncbi.nlm.nih.gov/Blast.cgi).

\section{Tolerance to Temperature, Low $\mathrm{pH}$, and Bile Salt}

The bacterial strains were tested for their ability to survive and grow at $37^{\circ} \mathrm{C}$, and to survive acidic conditions and the presence of bile salt. Overnight cultures of the bacteria were inoculated in the appropriate medium [lactobacilli: de Man, Rogosa, and Sharpe (MRS) broth (Difco; Becton, Dickinson and Company, Sparks, MD); lactococci: M17 broth (Merck KGaA, Darmstadt, Germany)] and in the same medium acidified to $\mathrm{pH}$ 2.0 or pH 3.0 with $0.1 \mathrm{M} \mathrm{HCl}$, or with $0.3 \%$ bile salt ( $\approx 6-7 \mathrm{~m} M$; Sigma-Aldrich, St. Louis, MO) added. The bacterial cultures were incubated at $37^{\circ} \mathrm{C}$ for $3 \mathrm{~h}$ before plating on their respective optimal media. All experiments were done in 3 replicates. 
Table 1. Bacterial strains and conditions for growth used in this study

\begin{tabular}{|c|c|c|c|c|}
\hline $\begin{array}{l}\text { Bacterial } \\
\text { species }\end{array}$ & Strain $^{1}$ & Origin & Media & $\begin{array}{c}\text { Growth } \\
\text { temperature, }{ }^{\circ} \mathrm{C}\end{array}$ \\
\hline Lactococcus lactis ssp. cremoris & Ar-1 & Milk & M17 & 22 \\
\hline Lc. lactis ssp. cremoris & Ar-1 & Milk & M17 & 22 \\
\hline Lc. lactis ssp. cremoris & $\mathrm{Bf}-2$ & Plant $^{2}$ & M17 & 22 \\
\hline Lc. lactis ssp. cremoris & $\mathrm{Bf}-3$ & Plant $^{2}$ & M17 & 22 \\
\hline Lactococcus lactis ssp. lactis & ML- $8^{3}$ & Milk & M17 & 30 \\
\hline Enterococcus hirae & INF E1 & Milk & M17 & 30 \\
\hline Lactobacillus rhamnosus & GG & Commercial strain & MRS & 30 \\
\hline Lactobacillus paracasei & INF-448 & Cheese & MRS & 30 \\
\hline Lb. paracasei & INF-456 & Cheese & MRS & 30 \\
\hline
\end{tabular}

\section{Tests with Human Gastric and Duodenal Juices Using an In Vitro Model System}

Human gastric juice (HGJ; $19.2 \mathrm{U} / \mathrm{mL}$ ) and duodenal juices (HDJ; $12.9 \mathrm{U} / \mathrm{mL}$ ) were collected from 20 individual healthy volunteers and pooled in 2 separate batches, 1 for HGJ and 1 for HDJ, to avoid variability. The aspiration procedures are described by Holm et al. (1988), in brief, a triple lumen silicone tube (Maxter Catheters, Marseille, France) enabled simultaneous instillation of a stimulation solution in the duodenum and aspiration of HGJ and HDJ. Correct placement of the tube was monitored by radiology. Continuous instillation $[100 \mathrm{~mL} / \mathrm{h}$ of the isotonic stimulatory solution $(17.5 \mathrm{~g}$ of sucrose/L, $450 \mathrm{mg}$ of $\mathrm{NaCl} / \mathrm{L}, 800 \mathrm{mg}$ of L-phenylalanine/L, and $575 \mathrm{mg}$ of L-valine/L in $\mathrm{H}_{2} \mathrm{O}$ )] and a continuous aspiration of gastric and duodenal fluids were performed simultaneously. The stimulation solution was instilled close to the papilla of Vater, whereas the HDJ was aspirated some $10 \mathrm{~cm}$ distally. Juices from the stomach were aspirated from the canalis ventriculi. The juices were collected in $50-\mathrm{mL}$ tubes on ice, inspected, and $\mathrm{pH}$ was measured periodically to avoid samples of mixed duodenal and gastric juices. The samples were centrifuged $(4,500 \times g$ for $10 \mathrm{~min})$ to remove mucous and cell debris before aliquots were frozen at -20 and then stored at $-80^{\circ} \mathrm{C}$. The enzyme activities were calculated by pepsin activity assay for HGJ using hemoglobin as substrate according to Sánchez-Chiang et al. (1987) and by the total proteolytic activity assay for HDJ with casein as a substrate according to Krogdahl and Holm (1979). The enzyme activity $(1 \mathrm{U})$ is defined as the amount $(\mathrm{mL})$ of HGJ or HDJ giving a difference in absorbance of 1.0 at $280 \mathrm{~nm}$ in 10 min at $37^{\circ} \mathrm{C}$.

Model Digestion of Bacterial Cultures. An overnight culture of each bacterial strain, $1 \%$ inocula in $40 \mathrm{~mL}$ of growth medium, were used in all of the experiments. After centrifugation for $30 \mathrm{~min}$ at 2400 $\times g$ (centrifuge 2010; Kubota Corp., Fujioka, Japan), the bacterial cell pellet was diluted with $40 \mathrm{~mL}$ of Ringer's solution. Ten milliliters of cell suspension was transferred to each of 2 plastic tubes equipped with sterilized magnetic stirrers and incubated in a water bath circulator (Julabo MB-7A; Julabo Labortechnik $\mathrm{GmbH}$, Seelbach, Germany) at $37^{\circ} \mathrm{C}$. One of the tubes was equipped with a pH meter (PHM 210 MeterLab; Radiometer Analytical SAS, Lyon, France) to check the $\mathrm{pH}$ during the digestion. The $\mathrm{pH}$ in the first step of digestion was adjusted to 2.5 with $1 \mathrm{M} \mathrm{HCl}$. After 5 $\min , 328 \mu \mathrm{L}$ of HGJ $(19.2 \mathrm{U} / \mathrm{mL})$ was added. After 60 min of digestion at $\mathrm{pH} 2.5$, the $\mathrm{pH}$ in the sample was adjusted to 7.0 with $1 \mathrm{M} \mathrm{NaOH}$ and then $1,440 \mu \mathrm{L}$ of HDJ $(12.9 \mathrm{U} / \mathrm{mL})$ was added, followed by incubation for another 60 min. Samples for determination of viable cell counts were taken after $0,5,65$, and $125 \mathrm{~min}$. The lactococci were enumerated on M17 agar plates, and the Lactococcus lactis ssp. lactis strains were incubated aerobically for $48 \mathrm{~h}$ at $30^{\circ} \mathrm{C}$. The Lc. lactis ssp. cremoris strains were, however, incubated anaerobically for $72 \mathrm{~h}$ at $22^{\circ} \mathrm{C}$. The lactobacilli were enumerated on MRS agar plates and incubated anaerobically for $48 \mathrm{~h}$ at $30^{\circ} \mathrm{C}$. Anaerobic conditions were created using a GasPak holding jar and Oxoid Atmosphere Generation System, AnaeroGen (Oxoid Ltd., Basingstoke, Hampshire, UK).

Digestion of Fermented Milk as a Carrier Matrix for the Bacteria. To evaluate the viability of the bacteria in a carrier matrix, fermented milk was used. Milk was fermented with a single strain of each bacterium. To improve the growth of lactobacilli, $1 \%$ sterilized $\left(121^{\circ} \mathrm{C}, 15 \mathrm{~min}\right) \mathrm{D}(+)$-glucose (Merck KGaA) was added to the milk with these strains. With the aim of removing any interference due to the MRS/M17 medium, the cultures were back-slopped twice. In the first step, $10 \mathrm{~mL}$ of sterilized skim milk $\left(95^{\circ} \mathrm{C}, 10 \mathrm{~min}\right)$, prepared from distilled water and $10 \%$ skim milk pow- 
der (Tine BA, Oslo, Norway) was inoculated with $1 \%$ $(100 \mu \mathrm{L})$ of an overnight broth culture and incubated. All of the Lc. lactis ssp. cremoris strains were incubated for $20 \mathrm{~h}$ at $22^{\circ} \mathrm{C}$, whereas the rest of the strains were incubated for $15 \mathrm{~h}$ at $30^{\circ} \mathrm{C}$. Subsequently, an aliquot equal to $1 \%(400 \mu \mathrm{L})$ was inoculated in $40 \mathrm{~mL}$ of sterilized $\left(95^{\circ} \mathrm{C}, 10 \mathrm{~min}\right)$ full-fat milk (Tine BA) with $3.2 \%$ protein and $3.9 \%$ fat and incubated under the same conditions as the previous step. After incubation, the fresh fermented milk was refrigerated for $24 \mathrm{~h}$ at $4^{\circ} \mathrm{C}$.

The fermented milk samples were then submitted to the in vitro digestive model system with HGJ and HDJ, following the protocol described previously (in the Model Digestion of Bacterial Cultures section). The amount of human juices added was calculated on the basis of enzyme activity per grams of protein $(20 \mathrm{U}$ of $\mathrm{HGJ} / \mathrm{g}$ of protein and $62.4 \mathrm{U}$ of HDJ/g of protein). Fermented milk $(10 \mathrm{~mL})$ was transferred to $50-\mathrm{mL}$ sterile plastic tubes equipped with sterilized magnetic stirrers and incubated in the water bath circulator at $37^{\circ} \mathrm{C}$. The $\mathrm{pH}$ was adjusted to 2.5 with $1 \mathrm{M} \mathrm{HCl}$, and after $5 \mathrm{~min}$ $300 \mu \mathrm{L}$ of HGJ $(19.2 \mathrm{U} / \mathrm{mL})$ was added. After $60 \mathrm{~min}$ of incubation, the $\mathrm{pH}$ was adjusted to 7.0 with $1 \mathrm{M} \mathrm{NaOH}$ and $1,316 \mu \mathrm{L}$ of HDJ $(12.9 \mathrm{U} / \mathrm{mL})$ was added, followed by $60 \mathrm{~min}$ of incubation. Samples of $0.5 \mathrm{~mL}$ were again drawn after $0,5,65$, and $125 \mathrm{~min}$, and the viable cell count was evaluated by plating on M17/MRS agar and incubated in the conditions shown in Table 1.

\section{Statistical Analyses}

Analysis of variance was performed using the SAS Enterprise guide 4.0 (SAS Institute Inc., Cary, NC). The treatment factors bacterial strain and media and their interaction formed the statistical model for the tests of the effects in adjusted media and in the digestion model, respectively. The Tukey simultaneous test was used to find differences between means (Snedecor and Cochran, 1989). For the statistical calculations, the following computed values were used:

$$
\begin{aligned}
\Delta \log _{3 \mathrm{~h}}= & \log \mathrm{cfu} / \mathrm{mL} \text { at time } 0-\log \mathrm{cfu} / \mathrm{mL} \\
& \text { after } 3 \mathrm{~h} \text { of incubation, }
\end{aligned}
$$

$$
\begin{gathered}
\Delta \log _{\text {digestion }}=\log \mathrm{cfu} / \mathrm{mL} \text { at time } 0-\log \mathrm{cfu} / \mathrm{mL} \\
\text { after } 125 \mathrm{~min} \text { of digestion (both gastric juice } \\
\text { and duodenum juice) }
\end{gathered}
$$$$
\Delta \log _{\text {gastric }}=\log \mathrm{cfu} / \mathrm{mL} \text { at time } 0-\log \mathrm{cfu} / \mathrm{mL}
$$
after $60 \mathrm{~min}$ in gastric juice,
$\Delta \log _{\text {duodenum }}=\log \mathrm{cfu} / \mathrm{mL}$ after $60 \mathrm{~min}$ in gastric juice - $\log \mathrm{cfu} / \mathrm{mL}$ after $60 \mathrm{~min}$ in duodenum juice.

\section{RESULTS}

\section{Growth and Survival of Single Bacterial Cultures in Broth and Adjusted Medium Containing 0.3\% Bile Salt and with $\mathrm{pH} 2$ and 3}

Incubation for $3 \mathrm{~h}$ at $37^{\circ} \mathrm{C}$ in normal and adjusted M17/MRS broths showed differences $(P<0.001)$ in $\Delta$ $\log _{3 \mathrm{~h}}$ between both the strains and the media (Table 2). In normal media, the Lactobacillus strains and Lactococcus lactis ssp. lactis ML8 and Enterococcus hirae INF E1 increased their cell numbers during $3 \mathrm{~h}$ at $37^{\circ} \mathrm{C}$, whereas the Lc. lactis ssp. cremoris strains had decreased viability $(P<0.05)$.

None of the Lactobacillus strains or E. hirae INF E1 were significantly affected by the bile salts, whereas the Lactococcus strains except Lactococcus lactis ssp. cremoris Af- 1 and Bf-2 showed decreased numbers $(P$ $<0.05$ ) when grown in bile salts. At reduced $\mathrm{pH}$, most of the tested strains had considerably decreased viability. However, after incubation at $\mathrm{pH} 3$ for $3 \mathrm{~h}$ at $37^{\circ} \mathrm{C}$, the Lactobacillus strains (GG, INF448, and INF456) survived and maintained an approximately constant viable cell count, whereas the viable cell counts of $L a c$ tococcus ssp. and E. hirae decreased $(P<0.05)$ and were decreased by about 2 to 3 logs. In particular, incubation at $\mathrm{pH} 3$ had a strong reducing effect on both the Lc. lactis ssp. cremoris strains, Bf-2 and Bf-3, and the enumerated numbers were less than $10^{2} \mathrm{cfu} / \mathrm{mL}$. After incubation at $\mathrm{pH} 2$ for $3 \mathrm{~h}$ at $37^{\circ} \mathrm{C}$, none of the strains were able to maintain a good survival rate. The enumerated numbers of all the Lactococcus strains and E. hirae were less than $10^{2} \mathrm{cfu} / \mathrm{mL}$ after $3 \mathrm{~h}$ of incubation. The $\Delta \log _{3 \mathrm{~h}}$ was less than 2 for Lc. lactis ssp. cremoris strains Bf- 2 and Bf- 3 . However, the numbers after inoculation at $\mathrm{pH} 2$ were very low and less than $\log 4$. The Lactobacillus strains showed better tolerance $(P<0.05)$ to the acidic environment compared with the lactococci and Enterococcus strain investigated, although their numbers were decreased from $\log 7$ to about $\log 4 \mathrm{cfu} / \mathrm{mL}$.

\section{Digestion of Single Bacterial Cultures and Fermented Milks with HGJ and HDJ in a Digestive Model System}

The production of the fermented milk and the following digestion were principally performed to study how fermented milk acts as a carrier matrix that could influence the viability of a strain during digestive con- 
Table 2. Survival of the strains in normal medium [de Man, Rogosa, and Sharpe (MRS)/M17] or medium with added $0.3 \%$ bile salt or $\mathrm{pH}$ adjusted to $\mathrm{pH} 2$ and $\mathrm{pH} 3$, given as change in colony-forming units of the strains during $3 \mathrm{~h}$ of incubation at $37^{\circ} \mathrm{C}^{1}$

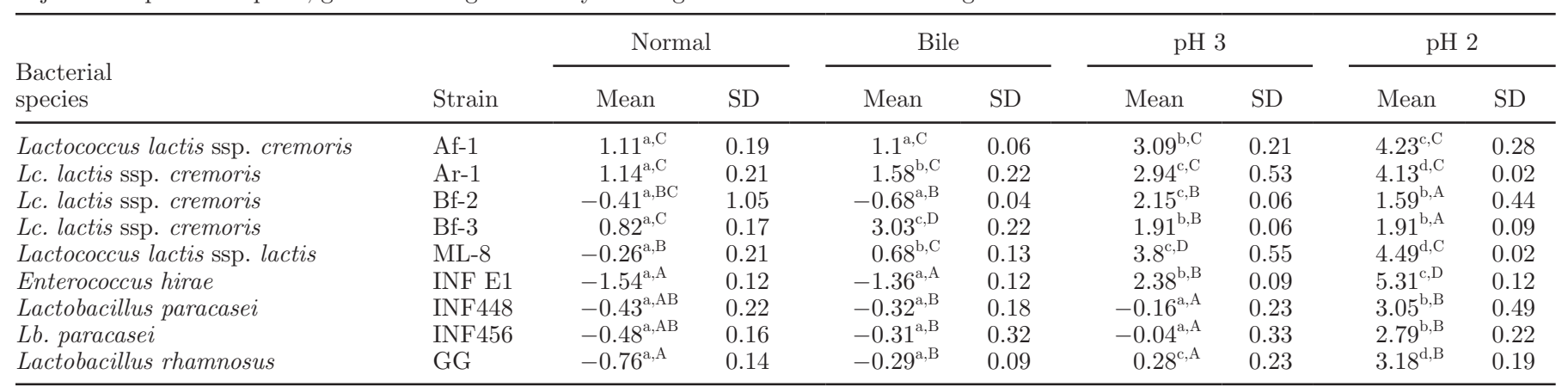

${ }^{\mathrm{a}-\mathrm{d}}$ Significant differences $(P<0.05)$ between the media for each strain (row factor) are shown by different lowercase superscript letters.

${ }^{\text {A-D }}$ Significant differences $(P<0.05)$ between each strain in each specific media (column factor) are shown by different uppercase superscript letters.

${ }^{1} \Delta \log 3 \mathrm{~h}=\log \mathrm{cfu} / \mathrm{mL}$ at time $0-\log \mathrm{cfu} / \mathrm{mL}$ at $3 \mathrm{~h}$.

ditions. During the model digestion using $\mathrm{HGJ} / \mathrm{pH} 2.5$ for $60 \mathrm{~min}$ and $\mathrm{HDJ} / \mathrm{pH} 7$ for $60 \mathrm{~min}$, differences $(P$ $<0.001)$ in viability were shown between the groups of lactococci and lactobacilli throughout the digestion process (Figure 1 and Figure 2). In general, the $L c$. lactis ssp. cremoris strains Af-1 and Bf-2 and Lc. lactis ssp. lactis ML8 had a poorer $(P<0.01)$ survival rate measured as viable cell count after digestion compared with the other strains investigated. The Lactobacillus ssp. retained a high cell number throughout the digestion and decreased by only 1 log, regardless of the matrix. After $2 \mathrm{~h}$ of digestion (125 min), Lactococcus lactis ssp. cremoris Ar-1 and Bf-2 and E. hirae benefitted ( $P$ $<0.01)$ from the presence of a fermented milk carrier matrix. On the other hand, Lc. lactis ssp. cremoris Af1, Lc. lactis ssp. lactis ML8, and Lactobacillus paracasei ssp. paracasei INF448 survived better as pure cultures than in fermented milk.

In HGJ, the viability of the washed cells of Lactococcus ssp. and $E$. hirae decreased $(P<0.001)$ during the first hour simulating the gastric tract. However, during the following hour at $\mathrm{pH} 7$ with HDJ (duodenum tract simulation), they were able to resume growth and the cell numbers increased approximately 1 to $2 \operatorname{logs}$ (Figure 1).

\section{DISCUSSION}

Five strains of Lc. lactis sp., 3 strains of lactobacilli, and 1 strain of Enterococcus were tested for their tolerance to acid, commercial bile salt and to gastric conditions through the exposure to HGJ and HDJ in a digestive model system. One of the main purposes of this study was to compare the traditional in vitro tests with a model system simulating human digestion. Furthermore, all of the selected lactococci and lactobacilli strains have interesting functional properties related to different food products. We, therefore, wanted to evaluate whether these strains could contribute with beneficial health functions, or even have the potential as probiotics for human consumption. Lactobacillus rhamnosus GG, one of the most studied probiotic bacterial strains on the market, was chosen as a probiotic control strain. All other strains than Lb. rhamnosus GG were food isolates and are, thus, not considered true probiotics. The one strain of Enterococcus was chosen because these are often found as nonstarter lactic acid bacteria in dairy products. They often dominate the intestine microbial flora and they might be potentially pathogenic (Klein, 2003). The analyses reported comprise a comprehensive in vitro testing regimen for evaluation of the survival of candidate probiotic bacteria during human digestion.

Evaluation of the probiotic properties of a strain requires extensive in vitro and in vivo investigation. It has been observed that many in vitro models can predict, with good approximation, the ability of a strain to survive in the human gastrointestinal tract and thereby confer a health benefit to the host. Such tests include investigations of the resistance to gastric acidity, bile salts, and pancreatic enzymes, the adherence to human epithelial cells using the cell lines, the immunomodulating effects, the antibiotic resistance profile and the hemolytic properties, the antimicrobial activity against pathogens, as well as competition with them for the sites of adhesion (Tannock, 2005).

The present study investigated the ability of 9 strains, 5 lactococci, 3 lactobacilli, and 1 enterococcal strain to survive conditions that mimic the digestive environment through a digestive model using HGJ. Human gastrointestinal enzymes differ from purified commercial nonhuman enzymes in the way that human gastro- 

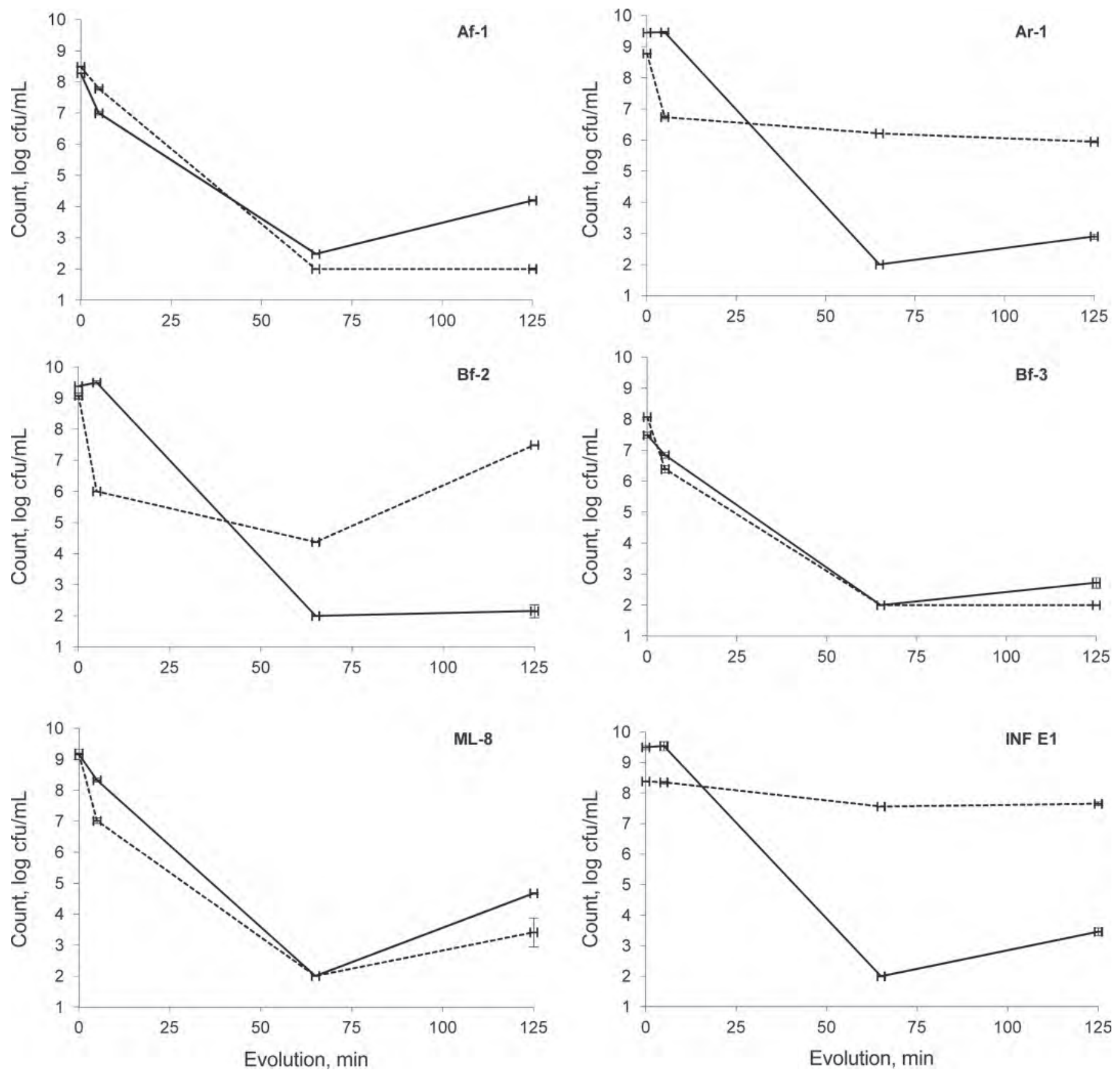

Figure 1. Comparison of the evolution of the Lactococcus strains (Lactococcus lactis ssp. cremoris Af-1, Ar-1, Bf-2, and Bf-3, and Lactococcus lactis ssp. lactis ML-8) and Enterococcus hirae INF E1 during digestion in gastric juice (0-65 min) and duodenum juice (65-125 min; mean \pm $\mathrm{SD}$ of $\mathrm{n}=2$ determinations). Solid lines (- $)$ : strain as washed cells; dotted lines (-----): strain in fermented milk. Log 2 means $\leq 100 \mathrm{cfu} /$ $\mathrm{mL}$; thus, $\log 2(=100)$ on the $\mathrm{y}$-axis might be a lower number than $100 \mathrm{cfu} / \mathrm{mL}$ because of the sensitivity of the plating method.

intestinal enzymes are complex and contain a mixture of proteases, amylases, and lipases that exist in different isoforms in combination with inhibitors, bile salts, bilirubin, cell mucus, and other minor components that may all influence the survival of bacteria (Ulleberg et al., 2011). Survival of digestive conditions is one of the fundamental properties of bacteria that are supposed to have effects beneficial to the consumers, and it is usually one of the first characteristics evaluated.

The acidity tolerance test showed that the Lactobacillus strains had a significant better acid tolerance than the lactococci under defined conditions. The 

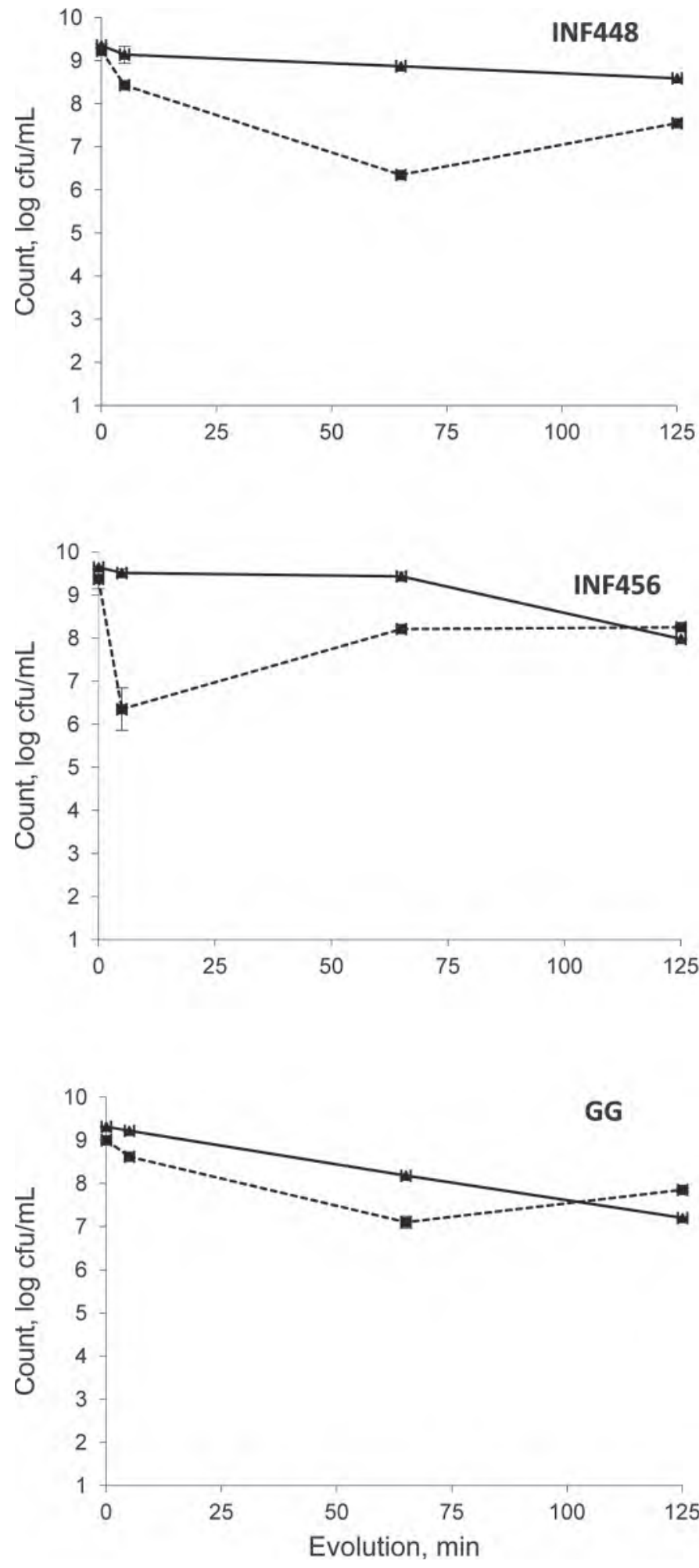

Figure 2. Comparison of the evolution of the Lactobacillus strains (Lactobacillus paracasei ssp. paracasei INF448 and INF456, and Lactobacillus rhamnosus GG) during digestion in gastric juice (0-65 min) and duodenum juice (65-125 min; mean \pm SD of $\mathrm{n}=2$ determinations). Solid lines (- $\longrightarrow$ : strain as washed cells; dotted lines $(-----)$ : strain in fermented milk.
2 lactobacilli investigated, $L b$. paracasei INF448 and Lactobacillus paracasei INF456 showed similar acid tolerance (confirmed by the Tukey test) as the wellknown probiotic strain $L b$. rhamnosus GG (Alander et al., 1999), used as a control. They maintained a high survival rate $\left(\sim 10^{7} \mathrm{cfu} / \mathrm{mL}\right)$ after $3 \mathrm{~h}$ at $\mathrm{pH} 3$, but their numbers were decreased to about $10^{4} \mathrm{cfu} / \mathrm{mL}$ when tested at $\mathrm{pH} 2$. This loss of viability observed in vitro between $\mathrm{pH} 3$ and $\mathrm{pH} 2$ is reported in several studies (Jacobsen et al., 1999; Schillinger et al., 2005). Among lactococci, it was possible to distinguish between the 2 subspecies. The Lc. lactis ssp. cremoris strains already decreased significantly in M17 broth $(\mathrm{pH} 7.2)$ at $37^{\circ} \mathrm{C}$ for $3 \mathrm{~h}$, demonstrating their inability to survive for this length of time at the human body temperature. Thus, as expected, at $\mathrm{pH} 3$ and $\mathrm{pH} 2$ their numbers of cells decreased to numbers less than $10^{3} \mathrm{cfu} / \mathrm{mL}$, lower than any levels generally accepted for probiotic bacteria (Kimoto-Nira et al., 2007). On the other hand, in the same tests at $\mathrm{pH} 7.2$ and $37^{\circ} \mathrm{C}$, Lc. lactis ssp. lactis ML8 and E. hirae INF E1 were able to grow, and at low $\mathrm{pH}$ they showed a survival rate slightly better than the strains of Lc. lactis ssp. cremoris. This seems to confirm earlier reports that state the subspecies Lc. lactis ssp. lactis as generally more robust and less affected by environmental changes than Lc. lactis ssp. cremoris (Kim et al., 2001).

Few of the strains were affected by the presence of bile salts, and only Lc. lactis ssp. cremoris Bf-3 seemed to be severely affected, confirming the results of similar work (Jacobsen et al., 1999; Lee et al., 2007), although other studies have concluded that bile salts had severe influence on bacterial survival (Coeuret et al., 2004). Surprisingly, 5 strains showed a weak increase in numbers of viable cells during the $3 \mathrm{~h}$ of incubation in $0.3 \%$ bile salt, a result not reported from other studies. Furthermore, as in the acid tolerance tests, the lactobacilli generally had a better performance than the lactococci, with the exception of the strains Lc. lactis ssp. cremoris Bf-2 and E. hirae INF E1, which also showed a high survival rate.

The survival of the lactobacilli was much better in the human model digestion system with HGJ and HDJ as compared with the standard acidity and bile tolerance tests, whereas the cocci, with some exceptions, performed similarly in both systems. The model digestion experiments gave the opportunity to simulate with more precision the gastrointestinal events occurring in the upper gastrointestinal tract, distinguishing the 2 phases: stomach and duodenum. The digestion presented 2 sequential phases in the same trial, the first part in acid conditions ( $\mathrm{pH} 2.5$ ) with HGJ, and the second step at neutral $\mathrm{pH} 7$ with HDJ (including natural pancreatic enzymes, inhibitors, and bile salts). The 
digestion of the pure bacterial strains demonstrated significant differences between lactobacilli and lactococci, with the latter being less tolerant than the lactobacilli strains. The digestion of the lactococcal stains and E. hirae INF E1 gave some surprising results. As expected, none of them survived in significant numbers after exposure to the conditions in the stomach, $\mathrm{pH} 2.5$ with HGJ. In fact, after the gastric phase, their viable cell numbers were below $10^{2} \mathrm{cfu} / \mathrm{mL}$. However, after the subsequent duodenal phase, the cell numbers increased by approximately 1 to 2 logs. This could mean that lactococci and enterococci after a period of acid stress are able to resurrect their viability if they are exposed to more suitable conditions like those in the small intestine. This aspect is indeed very interesting because it is in the intestine that functional or probiotic bacteria confer their health benefit to the host. It also implies that bacteria not regarded as probiotic but yet with potential health-related useful properties, like the exopolysaccharide-producing lactococci, still may have the possibility of a positive effect on the consumer.

The digestions of the fermented milks were performed with a protocol similar to the digestion of pure bacterial cultures to compare them and to evaluate how fermented milk as a carrier matrix could influence the viability of the strains. The initial hypothesis was that the fermented milks should give protection to the bacteria through the digestive tract, but the tests revealed strain-dependent results. At the end of the fermented milk digestion, the Lactococcus strains Af- 1 and ML-8 and Lb. paracasei INF448 showed lower numbers of viable cells compared with digestion of pure bacterial cells. In contrast, the Lactococcus strains Ar1, Bf-2, and E. hirae INF E1, Lb. paracasei INF456, and the commercial probiotic strain Lb. rhamnosus GG showed higher numbers of viable counts compared with the results from the digestion of the pure cultures. In particular, the carrier matrix improved the viability of the Lactococcus strains Ar- $1, \mathrm{Bf}-2$, and E. hirae INF E1 during the incubation in gastric conditions. These results seem to confirm that foods, such as fermented milks, could be a protective matrix enhancing survival of bacteria (Schillinger et al., 2005). In addition, as reported by Kim et al. (1999) and others (De Angelis and Gobbetti, 2004), this improvement could be an effect of the adaptive responses to acid stress. The bacteria were exposed to sublethal acid conditions (the acid $\mathrm{pH}$ of the fermented milk) before digestion and this could contribute to the observed protection against the subsequent exposure to normally lethal acidic levels ( $\mathrm{pH}$ of the stomach).

Until now, species in the Lactobacillus and Bifidobacterium genera commonly isolated from the intestine have received the most attention in the search for bacteria with positive health-related properties and as candidates for new probiotic strains. This study confirms that lactobacilli have potential as functional and even as probiotic strains, as they showed better tolerance overall to the conditions mimicking the environment in the digestive tract. The $L b$. paracasei INF448 and Lb. paracasei INF456 strains tested showed very good acid and bile tolerance and high numbers of viable cells after digestion, both as pure bacterial cultures and in a food matrix such as fermented milk. These strains were originally isolated from ripened cheese and have been used successfully as adjunct cultures in experiments developing cheese. Several aspects of their metabolism have been investigated (Skeie et al., 2008). Therefore, it would be interesting to evaluate functional properties of these 2 strains further for future exploitation of their potential as functional bacteria in food, or even as probiotics.

Enterococci are versatile bacteria that are part of the commensal human microbiota and are generally regarded as highly adapted to surviving the human digestive system. In addition, enterococci occur frequently in fermented meat and milk products, including cheese. Certain strains of enterococci are included in probiotic formulas and, as such, are regarded as beneficial to human health. We investigated an E. hirae strain isolated from milk for its performance in an in vitro digestion model. Our results showed that this strain benefitted from the protective matrix of fermented milk through good survival during and after the digestion. These results are comparable to what has been reported for the closely related species Enterococcus faecium (Klein, 2003).

One of the aims of the current study was to investigate the capacity of Lactococcus spp. as functional bacteria in foods and whether they are able to enter the intestine, although they are formally not considered normal inhabitants of the intestine. Until now only a few investigations have been conducted, showing that some lactococcal strains were able to survive at low $\mathrm{pH}$ and in the presence of bile salts (Kimoto-Nira et al., 2007; Lee et al., 2007). Among the lactococci tested in the present study, none have clearly shown a strong tolerance both to low $\mathrm{pH}$ and bile salts, although the strains Lc. lactis ssp. cremoris Ar-1 and Bf- 2 have displayed a good survival rate in presence of the fermented milk as carrier matrix. This result is especially interesting, as these specific strains are exopolysaccharide-producing bacteria in ropy milk, a traditional Nordic product reported to have beneficial effects on consumer health (Nilsson and Nilsson, 1958; Kitazawa et al., 1991; Nakajima et al., 1992; Kitazawa et al., 1993). 


\section{ACKNOWLEDGMENTS}

This work has been funded by a grant from the Norwegian Research Council (Oslo, Norway), the Norwegian Foundation for Research Levy on Agricultural Products (Oslo, Norway), the Norwegian Agricultural Agreement Research Fund (Oslo, Norway), and TINE SA (Oslo, Norway). We also thank Østfold Hospital (Moss, Norway) for extracting the gastric and duodenum juice.

\section{REFERENCES}

Alander, M., R. Satokari, R. Korpela, M. Saxelin, T. Vilpponen-Salmela, T. Mattila-Sandholm, and A. von Wright. 1999. Persistence of colonization of human colonic mucosa by a probiotic strain, Lactobacillus rhamnosus GG, after oral consumption. Appl. Environ. Microbiol. 65:351-354.

Borchers, A. T., C. Selmi, F. J. Meyers, C. L. Keen, and M. E. Gershwin. 2009. Probiotics and immunity. J. Gastroenterol. 44:26-46. doi:10.1007/s00535-008-2296-0.

Coeuret, V., M. Gueguen, and J. P. Vernoux. 2004. In vitro screening of potential probiotic activities of selected lactobacilli isolated from unpasteurized milk products for incorporation into soft cheese. J. Dairy Res. 71:451-460.

De Angelis, M., and M. Gobbetti. 2004. Environmental stress responses in Lactobacillus: A review. Proteomics 4:106-122. doi:10.1002/ pmic.200300497.

de Vrese, M., and J. Schrezenmeir. 2008. Probiotics, prebiotics, and synbiotics. Adv. Biochem. Eng. Biotechnol. 111:1-66. doi:10.1007/10_2008_097.

Ekmekcioglu, C. 2002. A physiological approach for preparing and conducting intestinal bioavailability studies using experimental systems. Food Chem. 76:225-230. doi:10.1016/S03088146(01)00291-6.

Fondén, R., K. Leporanta, and U. Svensson. 2006. Nordic/Scandinavian fermented milk products. Pages 156-173 in Fermented Milks. A. Y. Tamine, ed. Blackwell Science/SDT, Oxford, UK.

Furuset, K. 2005. Butterwort and butterwort ropy milk. Naturen 5:206-214. (Tettegras og tettemelk).

Furuset, K. 2008. The role of butterwort in butterwort ropy milk. Blyttia 66:55-62. (Tettegrasets rolle i tettemelk).

Holm, H., A. Krogdahl, and L. E. Hanssen. 1988. High and low inhibitor soybean meals affect human duodenal proteinase activity differently: In vitro comparison of proteinase inhibition. J. Nutr. 118:521-525

Holzapfel, W. H., P. Haberer, J. Snel, U. Schillinger, and J. H. Huis in't Veld. 1998. Overview of gut flora and probiotics. Int. J. Food Microbiol. 41:85-101. doi:10.1016/S0168-1605(98)00044-0.

Jacobsen, C. N., V. Rosenfeldt Nielsen, A. E. Hayford, P. L. Møller, K. F. Michaelsen, A. Pærregaard, B. Sandström, M. Tvede, and M. Jakobsen. 1999. Screening of probiotic activities of forty-seven strains of Lactobacillus spp. by in vitro techniques and evaluation of the colonization ability of five selected strains in humans. Appl. Environ. Microbiol. 65:4949-4956.

Kim, W. S., J. Ren, and N. W. Dunn. 1999. Differentiation of Lactococcus lactis subspecies lactis and subspecies cremoris strains by their adaptive response to stresses. FEMS Microbiol. Lett. 171:57-65.
Kim, W. S., J. Ren, and N. W. Dunn. 2001. Assessment of the tolerance of Lactococcus lactis cells at elevated temperatures. Biotechnol. Lett. 23:1141-1145.

Kimoto-Nira, H., K. Mizumachi, M. Nomura, M. Kobayashi, Y. Fujita, T. Okamoto, I. Suzuki, N. M. Tsuji, J.-I. Kurisaki, and S. Ohmomo. 2007. Lactococcus sp. as potential probiotic lactic acid bacteria. Jpn. Agric. Res. Q. 41:181-189.

Kitazawa, H., M. Nomura, T. Itoh, and T. Yamaguchi. 1991. Functional alteration of macrophages by a slime-forming Lactococcus lactis ssp. cremoris. J. Dairy Sci. 74:2082-2088.

Kitazawa, H., T. Yamaguchi, M. Miura, T. Saito, and T. Itoh. 1993 B-cell mitogen produced by slime-forming, encapsulated Lactococcus lactis ssp. cremoris isolated from ropy sour milk, viili. J. Dairy Sci. 76:1514-1519.

Klein, G. 2003. Taxonomy, ecology and antibiotic resistance of enterococci from food and the gastro-intestinal tract. Int. J. Food Microbiol. 88:123-131. doi:10.1016/S0168-1605(03)00175-2.

Krogdahl, A., and H. Holm. 1979. Inhibition of human and rat pancreatic proteinases by crude and purified soybean proteinase inhibitors. J. Nutr. 109:551-558.

Lee, N.-K., J.-E. Noh, G.-H. Choi, E.-J. Park, H.-I. Chang, C.-W. Yun, S.-W. Kim, C.-W. Kang, Y.-C. Yoon, and H.-D. Paik. 2007. Potential probiotic properties of Lactococcus lactis NK34 isolated from jeotgal. Food Sci. Biotechnol. 16:843-847.

Nakajima, H., Y. Suzuki, H. Kaizu, and T. Hirota. 1992. Cholesterol lowering activity of ropy fermented milk. J. Food Sci. 57:13271329.

Nilsson, R., and G. Nilsson. 1958. Studies concerning Swedish ropy milk-The antibiotic qualities of ropy milk. Arch. Mikrobiol. 31:191-197.

Østlie, H. M., L. Eliassen, A. Florvaag, and S. Skeie. 2004. Phenotypic and PCR-based characterization of the microflora in Norvegia cheese during ripening. Int. J. Food Microbiol. 94:287-299.

Pfeiler, E. A., and T. R. Klaenhammer. 2007. The genomics of lactic acid bacteria. Trends Microbiol. 15:546-553. doi:10.1016/j. tim.2007.09.010.

Sánchez-Chiang, L., E. Cisternas, and O. Ponce. 1987. Partial purification of pepsins from adult and juvenile salmon fish Oncorhynchus keta. Effect of $\mathrm{NaCl}$ on proteolytic activities. Comp. Biochem. Physiol. B 87:793-797. doi:10.1016/0305-0491(87)90390-7.

Schillinger, U., C. Guigas, and W. H. Holzapfel. 2005. In vitro adherence and other properties of lactobacilli used in probiotic yoghurt-like products. Int. Dairy J. 15:1289-1297. doi:10.1016/j. idairyj.2004.12.008.

Skeie, S., A. Kieronczyk, S. Eidet, M. Reitan, K. Olsen, and H. Østlie. 2008. Interaction between starter bacteria and adjunct Lactobacillus plantarum INF $15 \mathrm{D}$ on the degradation of citrate, asparagine and aspartate in a washed-curd cheese. Int. Dairy J. 18:169-177. doi:10.1016/j.idairyj.2007.09.002.

Snedecor, G. W. M., and W. G. Cochran. 1989. Statistical Methods. 8th ed. Iowa State University Press, Ames.

Tannock, G. W. 2005. New perceptions of the gut microbiota: Implications for future research. Gastroenterol. Clin. North. Am. 34:361-382. doi:10.1016/j.gtc.2005.05.006.

Ulleberg, E. K., I. Comi, H. Holm, E. B. Herud, M. Jacobsen, and G. E. Vegarud. 2011. Human gastrointestinal juices intended for use in in vitro digestion models. Food Dig. doi:10.1007/s13228-011$0015-4$.

Zhu, Y., Y. Zhang, and Y. Li. 2009. Understanding the industrial application potential of lactic acid bacteria through genomics. Appl. Microbiol. Biotechnol. 83:597-610. doi:10.1007/s00253-009-20344 . 